BANCA D'ITALIA

E U R O S I S T E M A

Questioni di Economia e Finanza

(Occasional Papers)

Timely indicators for labour income inequality

by Francesca Carta 

BANCA D'ITALIA

E U R O S I S T E MA

\section{Questioni di Economia e Finanza}

(Occasional Papers)

Timely indicators for labour income inequality

by Francesca Carta

Number 503 - July 2019 
The series Occasional Papers presents studies and documents on issues pertaining to the institutional tasks of the Bank of Italy and the Eurosystem. The Occasional Papers appear alongside the Working Papers series which are specifically aimed at providing original contributions to economic research.

The Occasional Papers include studies conducted within the Bank of Italy, sometimes in cooperation with the Eurosystem or other institutions. The views expressed in the studies are those of the authors and do not involve the responsibility of the institutions to which they belong.

The series is available online at www.bancaditalia.it.

ISSN $1972-6627$ (print)

ISSN 1972-6643 (online)

Printed by the Printing and Publishing Division of the Bank of Italy 


\title{
TIMELY INDICATORS FOR LABOUR INCOME INEQUALITY
}

\author{
by Francesca Carta*
}

\begin{abstract}
In this paper I propose a methodology for obtaining timely indicators for labour income inequality using the Italian Labour Force Survey (ILFS), a database which collects detailed information not only on individuals' labour market status, but also on their households and wages. I develop a framework to estimate household labour income and I use it to construct timely indicators of the labour income distribution, to be used as complements to the standard and richer information provided by the household income surveys, like the Survey on Household Income and Wealth (SHIW) and the EU Statistics on Income and Living Conditions (EU-SILC). I discuss the assumptions and measurement issues underlying the proposed methodology and show that the ILFS-based Gini index closely tracks those calculated on standard household income surveys. The proposed measure is then a tool for monitoring the evolution of labour income inequality following labour market adjustments.
\end{abstract}

JEL Classification: C53, D31, E24 J21.

Keywords: inequality, employment.

\section{Contents}

1. Introduction .5

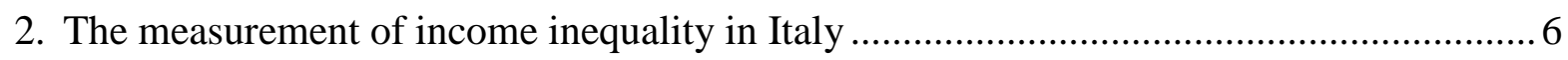

3. A methodology for recovering family labour income in the ILFS .................................. 8

3.1 Conceptual challenges in the estimation of labour income inequality with the ILFS .. 8



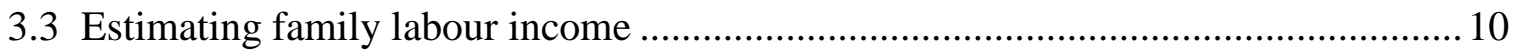

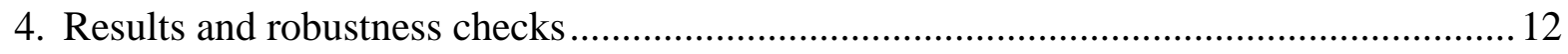

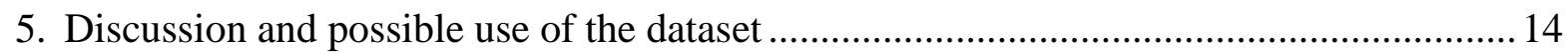

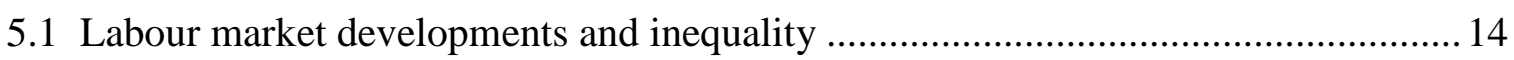

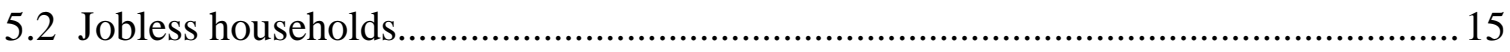

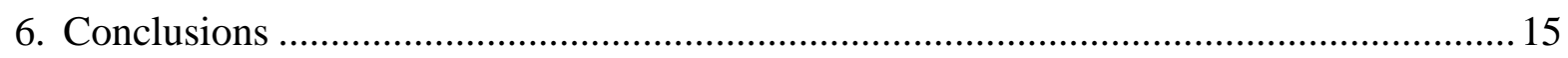

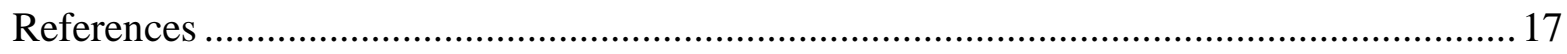



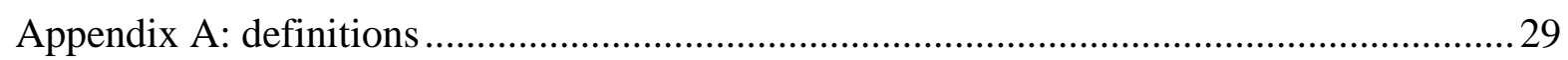

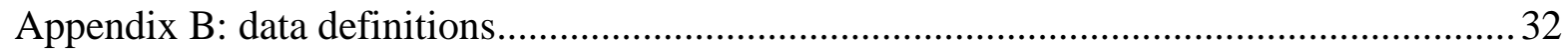

\footnotetext{
* Bank of Italy, Directorate General for Economics, Statistics and Research; Dondena Gender Initiative (Bocconi University).
} 



\section{Introduction ${ }^{1}$}

Although significant changes in the income distribution occur only in the long run, both economists and policymakers are increasingly valuing the availability of timely information on the developments of inequality and poverty. Such information would allow monitoring the effectiveness of redistributive policies and the distributional impact of changing macroeconomic conditions. However, the survey data required to construct indicators of income distribution are usually available with a significant delay, as in the case of the EU Statistics on Income and Living Conditions (EU-SILC), or with low time frequency (for instance, the Survey on Household Income and Wealth (SHIW) and the Household Finance and Consumption Survey (HFCS) are released every two years).

Tracking the evolution of inequality and poverty has become especially relevant in the aftermath of the Great Recession. In the period 2008-2016, average income inequality remained rather stable in the European Union, but with high within-country heterogeneity (Jenkins et al., 2012; Vacas-Soriano and Fernández-Macías, 2018). Poverty rates reached high levels, especially in those countries mostly hit by the sovereign debt crisis (European Parliament, 2016). ${ }^{2}$ These trends have challenged the ability of the European Welfare States to provide insurance against economic shocks, and have raised the need to monitor poverty and distributional conditions on a more frequent basis. Nowcasting ${ }^{3}$ of distributional indicators has become a priority for the European Commission, that in 2016 started publishing flash estimates of the at-risk-of-poverty rate and of the income quintile share ratio, obtained by using EUROMOD, the microsimulation model based on EU-SILC data.

The aim of the paper is to provide timely and yearly available indicators of labour income inequality by using a different data source, the microdata of the Italian Labour Force Survey (ILFS), which are released four times a year with a delay of just five-six months from the reference period. The information available in the ILFS allows me to focus only on labour income, which is, however, the main source of income for Italian households and one of the main drivers of income inequality in this country. ${ }^{4}$ To build a measure of

\footnotetext{
${ }^{1}$ Bank of Italy, DG Economics and Statistics. The views expressed in the article are those of the author only and do not involve the responsibility of the Bank of Italy. I am grateful to Effrosyni Adamopoulou, Gaetano Basso, Giulia Bovini, Andrea Brandolini, Emanuele Ciani, Federico Cingano, Marta De Philippis, Ivan Faiella, Sauro Mocetti, Marco Savegnago, Paolo Sestito and Eliana Viviano for very useful comments and suggestions. All errors are mine.

${ }^{2}$ Italy followed a similar pattern: while overall income inequality did not change much, individuals along the entire income distribution became poorer (Brandolini, 2014).

${ }^{3}$ Nowcasting is the prediction of the present, the very near future and the very recent past. Nowcasting techniques rely on timely information in order to nowcast key economic variables, such as e.g. GDP, that are typically collected at low frequency and published with long delays (BańBura et al., 2012).

${ }^{4}$ The trends in the Gini index on equivalised labour income are similar to those observed for the Gini index on equivalised disposable income as discussed more in details in the following.
} 
household labour income, I develop a methodology that relies on detailed available information on hours of work and monthly wages. Since the latter is observed only for employees, I impute self-employed income by estimating a Mincerian equation of hourly wages, and then I exploit additional information on self-employed income inferred from other data sources. Then, after running a bunch of robustness checks to validate the proposed methodology, I present up-to-date indicators for labour income inequality.

My analysis is related to the literature on nowcasting of inequality and poverty. The suggested methodology has at least two advantages with respect to existing methods. First, while previous studies use microsimulation techniques to update information on past income sources, ${ }^{5}$ my methodology draws on promptly available data. Second, I am able to reduce the delay to only five-six months, while in these works the delay is about one year. Moreover, by being the main data source for labour market statistics, the ILFS also represents the ideal venue for the analysis of the links between labour market developments and distributional issues. However, given the limits of the data (lack of other sources of income and no information of self-employed earnings), the proposed indicator is meant not to substitute standard income measures, but to complement them, by providing information on how much labour income inequality is arising because of labour market dynamics.

The paper is organized as follows. Section 2 explores the different data sources and indicators usually employed to investigate the distributional issues in Italy. Section 3 first discusses the challenges of using the ILFS to predict distributional indicators of household labour income, and then it illustrates the methodology followed to obtain its measure in the ILFS. Section 4 provides an inequality indicator for the ILFS measure of household labour income, which is then compared with that computed on the basis of the SHIW. Section 5 provides further additional analyses that can be carried out having updated information both on employment and labour income. Finally, Section 6 concludes.

\section{The measurement of income inequality in Italy}

In Italy the analysis of income inequality and poverty (see Appendix A for definitions) is traditionally based on three data sources: the SHIW, administered by the Bank of Italy, the EU-SILC, collected by the Italian National Institute of Statistics (Istat), and the Household Budget Survey (HBS), also run by the Istat.

\footnotetext{
${ }^{5}$ Navicke et al. (2014) and Gasior and Rastrigina (2017) use this methodology with EUROMODE to estimate the income poverty rate; Fontaine and Fourcot (2015) use INES, the French microsimulation model based on the Tax and Social Incomes survey (ERFS), to provide the Gini index, the p90/p10 income ratio and the poverty rate.
} 
The SHIW ${ }^{6}$ provides the longest record of household income data for Italy, and it is available since 1977. Since 2010 it has become part of Eurosystem's HFCS Survey, coordinated by the European Central Bank, that provides a harmonized dataset for some Euro-area countries as for income, wealth and consumption data; previously, the SHIW was also part of the Luxembourg Income Study (LIS). The EU-SILC is available since 2006 and provides net and gross income data for the previous year relatively to the survey year. It is the main data source to compare income and inequality across European countries.

Despite some differences in income concepts (mainly related to the imputation of rents for owner-occupied dwellings, fringe benefits and other non-cash compensation), sampling methods and sample size, the Gini index for equivalised ${ }^{7}$ disposable income calculated on the two datasets shows a rather similar pattern (Figure 1). The latest available information refers to the year 2016. The SHIW released this information in March 2018 (with about one year delay) and the EU-SILC released it in December 2018 (two-year delay). In the following, I will mainly refer to the SHIW which has the disadvantage of not being available every year but, when available, has a shorter delay.

As for poverty, the main indicators are provided by the HBS which collects all the expenditures incurred by resident households in a given month to purchase goods and services exclusively devoted to household consumption. The last available data refer to 2017 and were released in July 2018. These indicators, which measure absolute and relative poverty (see Appendix A for definitions), are computed on the basis of consumption expenditure (not on income). ${ }^{8}$ Consumption-based indicators are usually preferred, when available, to the ones based on income since they refer to the poor's conditions in terms of inability to afford a given level of expenditure considered necessary for a decent life. Income poverty indicators can also be calculated by using the SHIW and the EU-SILC data. $^{9}$

The overall picture provided by the different data sources suggests that in Italy income inequality has raised very modestly during the Great Recession and its aftermath, but poverty dramatically increased (Sestito, 2016), especially among households whose primary earner is young or foreign born (Brandolini et al., 2018). The incidence of absolute

\footnotetext{
${ }^{6}$ Papers based on the SHIW for the analysis of income inequality are Brandolini et al. (2002) and Jappelli and Pistaferri (2010) among the others; for a comparison across the different datasets see Galbraith et al. (2016).

${ }^{7}$ Equivalised disposable income is equal to family income divided by an equivalence scale (that can be equal to the square root of the household size or the OECD-modified equivalence scale); this normalization allows to take into account the existence of economies of scale within the household.

${ }^{8}$ Poverty indicators similarly to the ones provided by Istat are not available at international level.

${ }^{9}$ The share of individuals at risk of poverty or social exclusion is the leading indicator within the Europe 2020 framework and used for comparisons among European countries. See Appendix A for definitions.
} 
poverty among individuals more than doubled since 2006, from 2.9 to 8.4 per cent in $2017 .^{10}$

To have some indications for the most recent period, 2017-2018, I exploit the available information in the ILFS, currently updated at the $4^{\text {th }}$ trimester of 2018.

\section{A methodology for recovering family labour income in the ILFS}

\subsection{Conceptual challenges in the estimation of labour income inequality with}

\section{the ILFS}

The ILFS is a quarterly rolling panel dataset collected by the Istat. The dataset contains detailed information on the labor market status, family structure and other socio-economic characteristics for about 250,000 households and 600,000 individuals per year. The ILFS is the main dataset used to provide the official statistics on the labour market and is part the of the European Labor Force Survey. Despite it is not a household income survey, since 2009 employees are asked about their net regular salary earned one month before (no $13^{\text {th }}$ or $14^{\text {th }}$ month's salary), excluding those extra-payments that are not commonly included in the monthly pay (see Appendix B for more details). This is the key variable in order to measure monthly family and equivalised labour income.

The use of the ILFS restricts the analysis only to labour income, since no indications on other incomes (transfers, capital income) can be inferred. However, labour income is not only a large share of disposable income for the Italian population (in terms of equivalised person, Figure 2), but the dispersion of its distribution, measured by the Gini index on equivalised income, closely resembles the dispersion of the distribution of disposable income, both in levels and in trends (Figure 3). ${ }^{11}$ A decomposition of the Gini index on equivalised disposable income by income source (Shorrocks, 1982) confirms this evidence

\footnotetext{
${ }^{10}$ The absolute poverty rate increased from 2.1 per cent in 2007 to 6.1 in 2017 among households whose head of the family is employed; over the same period, if the reference person is unemployed the incidence of absolute poverty rose from 7.0 to 26.7 . The evidence suggests that being employed seems to no longer ensure against the risk of poverty. But some caveats are important. First, headcount employment provides only a partial picture of labour market developments (Brandolini and Viviano, 2016): being simply the proportion of working-age people who have been working for at least one hour in the reference week (ILO definition), it does not consider working times and contract duration, as well as important determinants of earnings. Second, employment is measured at individual level, while welfare at family level: labour supply interactions within the household affects family welfare and are not detected by the simple employment rate.

${ }^{11}$ Levels of the Gini index on equivalised labour and disposable income are largely similar when focusing on "younger" families, those where there are not retirees and the Reference Person is 15-64 years old. These families are less likely to rely on pension income. These represent 60 per cent of Italian families, involving around 70 per cent of the population. Levels of the Gini index differ when looking at all families; the Gini index on equivalised labour income is higher that the Gini index on equivalised disposable income since families relying on other incomes than labour income are counted as having zero income. However, trends are largely similar (Figure 3).
} 
(see also Raitano, 2016). Intuitively, the decomposition shows that labour income ${ }^{12}$ is one of the main drivers of income inequality; it contributes to income inequality by 57 per cent (Table 3). Thus, labour income inequality is an important contributor to the distribution of total income.

On top of this limitation, the suitability of the ILFS to consistently predict the labour income distribution relies on two main assumptions.

First, even restricting the analysis only to labour income, indicators predicted in the ILFS may diverge from those obtained from standard household income surveys (SHIW or SILC) because of differences in the accounting period over which the various income components are measured. While in the ILFS the accounting period for wages is the month, in the SHIW and EU-SILC it is the year for all the income sources. Depending on the differences in months worked along the labour income distribution, the level of inequality estimated on monthly income can significantly diverge from that measured on yearly income. For example, if at the bottom of the distribution jobs are more unstable and it is less likely to work for the full year, inequality and poverty are underestimated when looking at monthly rather than yearly incomes. However, comparing the distribution of monthly and yearly equivalised labour income in the SHIW, ${ }^{13}$ I find that the Gini index for most recent years are similar in levels and trends (Figure 4). Moreover, according to Böheim and Jenkins (2006), differences in the accounting period (month vs. year) do not remarkably affect the shape of the income distribution and its trends. This is due to at least two explanations: 1) current income, as measured by the ILFS, refers to "regular pay" rather than simply the last pay; 2) changes in employment or in the demographic composition of the household are rather small or random over the month/year. ${ }^{14}$

Second, self-employed income is not provided in the ILFS and has to be estimated. In subsection 3.2 I suggest an imputation method based on standard methodologies using contemporaneous information on employees' wages. This imputation involves around 23 per cent of total employment; moreover, considering that even in standard household income surveys self-employed incomes are hardly measurable in a reliable way (Brandolini, 2000), I believe that imputing self-employed income is a minor limitation of my work. In Section 4 I provide evidence of how imputation fits the data taken from the SHIW.

\footnotetext{
${ }^{12}$ Labour income is referred to all the population, thus it takes into account also those who are not employed.

${ }^{13}$ Monthly labour income in the SHIW is obtained by the ratio between yearly labour income and months worked over the year.

14 The SHIW refers to the yearly economic conditions of households and the reported employment condition is the prevalent employment status over the year. The ILFS reports current wage, that is the last regular monthly wage at the time of the interview.
} 


\subsection{The data}

In order to recover a measure of family labour income in the ILFS I mainly rely on two pieces of information: employees' monthly wages and weekly hours of work.

Information on monthly wages is available only since 2009; then, I use data for the period from 2009 to 2018 (the ILFS has been collected since 1992). The salary is reported in bin of 10 euros for amounts between 250 and 3000 euros; for lower and higher levels, there are two categories, respectively: $250-$ euros and $3000+$ euros. Thus, the variable is not very detailed at the bottom and at the top of the monthly wage distribution. ${ }^{15}$

Hours worked are collected for all workers (including self-employed) and refer to the number of weekly hours usually worked in the last four weeks. Thus, I can calculate a proxy for hourly wages (described in the next subsection) under the assumption that individuals work for the full month. Despite monthly wage and weekly hours worked refer to two different time periods, the fact that questions are referred to "regularly" earned wage and "usually" worked hours is reassuring that the information is internally consistent.

\subsection{Estimating family labour income}

I propose a simulation exercise aimed at estimating family labour income by exploiting the detailed information on labour markets status and family background of the respondents. I proceed by steps.

First, I only have information on employees' wage. To estimate the monthly labour income of self-employed workers I follow a methodology in the spirit of the one used in the National Accounts (Istat, 2014). I impute the employees' hourly wage $\left(w_{i t}\right)^{16}$ to selfemployed workers by means of a simple linear regression model a la Mincer. I regress the logarithm of hourly wage on a set of standard regressing variables $\left(X_{i t}\right)$ : those related to the individual (i.e. sex, age, level of education, civil status and citizenship) and her working status (working time schedule, sector), and those related to her family background (number of children, province of residence):

$$
\log \left(w_{i t}\right)=X_{i t}^{\prime} \beta_{t}+\varepsilon_{i t} \text { for } t=2009 / 2018
$$

\footnotetext{
${ }^{15}$ However, in years 2008-2016, the shares of employees who reported monthly wages below 250 and above 3000 are, respectively, on average 1.2 and 1.8 per cent by year (from the SHIW; monthly wage is obtained as the ratio between annual earnings and months worked in one year).

${ }^{16}$ This is obtained as the ratio between monthly wage and weekly working hours times the average number of working weeks in one month, 4.3 .
} 
Main results are reported in Table 1 . Hourly wages are positively correlated with education and age, negatively with being female or migrant. Coefficients are stable across the considered years. Full-time employees have earned an hourly wage lower than the mean, especially in most recent years (2013-2018).

The regression model only explains a fraction (between 29.2 and 32.0 per cent) of the wage distribution. Hence, the distribution of the imputed $\log$ wages $\log \left(w_{l t}\right)=X_{i t}^{\prime} \hat{\beta}_{t}$ for $t=$ $2009 / 2018$ is less dispersed than that of the observed variable. To correct for this, I add to the predicted mean values an error term $\left(\eta_{i t}\right)$, randomly drawn from a normal distribution with zero mean and variance equal to the residual variance of the estimated regression model (RMSE): ${ }^{17}$

$$
\left.\operatorname{log(w_{lt}}\right)^{A D J}=\log \left(w_{l t}\right)+\eta_{i t}, \eta_{i t} \sim N\left(0, \widehat{R M S E}_{t}\right) \text { for } t=2009 / 2018
$$

Finally, in order to take into account that, even controlling for observable characteristics, the self-employed hourly income might statistically differ from employees' hourly wage, I estimate a Mincer equation model as the one above for all workers, both employees and self-employed, by using the SHIW data. In Table 2 I detect that over the period 2010-2016 being an employee was associated to an hourly wage "premium" of about 10.0 per cent, on average; the premium was increasing over time. On the contrary, in 2008 it was associated to a penalty of about 4 per cent. ${ }^{18}$ To account for this, I correct the predicted hourly wage of self-employed as follows: ${ }^{19}$

$$
\widehat{w}_{i t}^{g}=\frac{\exp \left(\log \left(w_{t}\right)^{A D J}\right)}{1+g_{t}} \text { for } t=2009 / 2018
$$

where $g_{t}$ the coefficient associated to the dummy "employee" in Table 2.

Given the predicted hourly income, the monthly income of self-employed is then obtained as the product of the predicted hourly income times hours worked in one month (that is, hours usually worked in one week times the average number of weeks per month, 4.3).

\footnotetext{
${ }^{17}$ I preferred this correction with respect to one based on the variance of self-employed income estimated in the SHIW; however, results look similar and are available upon request.

18 These developments would reflect the fact that self-employed income is more cyclical than wages and that in Italy self-employment is on a decreasing trend (Bovini and Viviano, 2018); thus, it is possible that some negative not-observed selection into self-employment would play a role in explaining this evidence.

${ }^{19}$ For those years in which SHIW is not available (odd years) we take the average gap among the closest available years.
} 
Second, since the focus of my analysis is on labour income, I exclude those families who are less likely to rely on labour as main source of income. Thus, I drop those households in which there is at least one retiree; moreover, I select only households whose Reference Person (RP) is between 15 and 64 years old. This selection is necessary to avoid classifying as zero-income those households with income from pension, which would upwards bias the number of individuals with no income. These selected families are 60 per cent of Italian families, involving around 70 per cent of the population.

Third, individuals' labour income is aggregated at the family level. In order to account for family size and the age of its members, I also normalized family income by adopting the OECD-modified equivalence scale. ${ }^{20}$ In this way, I obtain a measure of welfare that is comparable across individuals.

\section{Results and robustness checks}

Figures 5, 6 and 7 compare the distribution of different income measures computed in the ILFS and in the SHIW across those years currently available for both surveys (from 2010 to 2016). The ILFS income measures would have been available on a yearly basis and six months before those obtained from the SHIW. Figure 5 compares monthly wages; the ILFS measure is computed from the raw data available in the survey, that is censored from above and from below; the SHIW variable is obtained by dividing annual earnings by the number of months worked in the reference year. Despite censoring of the ILFS wage, the two distributions look pretty similar; the ILFS wage distribution is rather more shifted towards the left, mainly because reported wages exclude bonuses, overtime and extra-salary. Also the different nature of the surveys - the yearly basis in the case of the SHIW, quarterly for the ILFS with last month regular pay data - contributes to explain the higher share of the "poor" in the ILFS. Figure 6 compares the distribution of the imputed self-employed income in the ILFS and the observed self-employed income in the SHIW; it is visible that the imputation performs well in replicating the distribution of self-employed income observed in the SHIW, which shows a larger share of low self-employed incomes because I also kept those reporting zero or small amount of income. Finally, in Figure 7 it is evident that the distribution of monthly equivalised labour income is largely similar in the SHIW and in the ILFS; the share of individuals with zero income is higher in the ILFS than in the SHIW, reflecting the same evidence observed for wages in Figure 5, maybe because these individuals were able to earn a positive labour income over the entire year but not in a given month, as measured by the ILFS.

\footnotetext{
${ }^{20}$ The OECD-modified equivalence scale is a factor computed on the basis of the size of the family and on the age of its members. It represents the needs of the family allowing for the presence of economies of scale in consumption. The OECD-modified scale assigns a value of 1 to the household head, 0.5 to each additional adult member and 0.3 to each child.
} 
Figure 8 compares the Gini index computed on monthly equivalised labour income in the SHIW $^{21}$ and in the ILFS on the selected sample of individuals; both the developments and the levels of the indices are rather aligned, suggesting that the methodology followed provides a good fit for the measurement of labour income inequality. This is even more evident comparing the bi-annual changes in the indices. I also provide an indicator for labour income poverty, measuring those individuals with an equivalised income lower than 60 per cent the annual median equivalised labour income. The indicator computed in the ILFS is not much accurate in levels, mainly due to the different accounting period of the surveys. Thus, it is more likely to observe extreme low values in the ILFS and to obtain higher values of the poverty rate (as also inferred from the inspection of Figure 7); while this does not affect much inequality measure, since the Gini index is less sensitive to changes taking place at the extremes of the distribution (Jenkins, 2009), it may be more relevant as for an indicator which looks at the bottom of the distribution. However, dynamics of the two indicators for labour income poverty are rather similar and show that the labour income poverty rate is still rather at high levels despite the employment recovery started in 2014 (Figure 9).

Since the ILFS monthly wage is censored both from below and from above, respectively at thresholds 250 and 3000 euros, the presence of censoring may underestimate both income inequality and poverty measures in the ILFS. I run the following checks in order to address the robustness of my results.

First, I assume that within the interval [0-250], employees' monthly wages are distributed according to a uniform distribution and I give the mean value to those monthly wages lower than 250 , i.e. 125 rather than the censored value. For values higher than 3000 , I assume a Pareto distribution. Figure 10 shows that the developments of the Gini index for the corrected income variable are the same of the Gini index for the original one; while in some years the levels are more diverging from the Gini computed on the SHIW income, the correction for censoring allow to proxy slightly better the bi-annual changes (the variable "delta" in the Figure). The labour income poverty rate for the corrected income variable is only slightly higher than that computed for the censored variable.

Second, I apply the same censoring of the ILFS variable to monthly labour income in the SHIW. Figure 11 shows that Gini index computed in SHIW starting from censored monthly wages is closer to the Gini index in the ILFS; however, changes in the index over time do not differ from those observed for the original distribution of equivalised labour income.

Finally, in Figure 12 I provide the time series, for available years, of the Gini index on equivalised monthly labour income in the ILFS. This is the prediction of the SHIW index

\footnotetext{
${ }^{21}$ Monthly labour income in the is computed as the ratio of annual labour income and the number of months worked during the year.
} 
for labour income, since it would be available on a yearly basis and six months before the figure obtained from the SHIW.

\section{Discussion and possible use of the dataset}

\subsection{Labour market developments and inequality}

The availability, within the same dataset, of detailed labour market information and family labour income allows me to link labour market developments and individuals' wellbeing.

In Table 4 I decompose the Gini index on equivalised labour income $(G)$ in two components (see Appendix A): one attributed to the share of individuals living in households without labour income $(1-e)$, which measures how many individuals cannot rely on it (despite being in an "active" household ${ }^{22}$ ), and another that is the dispersion of equivalised labour income among individuals living in households with positive values of labour income $\left(G_{e}\right)$, weighted by their share over the reference population:

$$
G=(1-e)+e^{*} G_{e} .
$$

Results in Table 4 point out that during the period 2009-2014 the increase of the Gini index on equivalised labour income (by 3.1 p.p.) among individuals living in "active households" was almost entirely driven by the increase in the share of individuals in households without labour income. In the following period, from 2014 to 2018, the decline in the share of individuals leaving in households without employed and, to a less extent, the reduction in the dispersion of equivalised labour income among those living in households with positive earnings contributed to the reduction of the Gini index by 1.4 p.p., at 35.4 in 2018.

Similar developments are detected across macro-areas. Over the period 2009-2018 the Gini index on equivalised labour income rose by 3.6 p.p. in the Southern Regions, only by 1.1 p.p. in Centre-North of Italy. The higher level of inequality in the South is mainly driven by lower employment rates; these are associated to a higher number of families without labour income and to a lower share of families with more than one member that is employed (Ciani and Torrini, 2019).

\footnotetext{
${ }^{22}$ It is useful to remind that the analysis focuses only on those households who are more likely to rely on labour income - those with no retirees and whose RP is 15-64 years old.
} 


\subsection{Jobless households}

Eurostat provides an indicator strictly linked to the employment status and based on the EU Labour Force Survey. This is the proportion of people living in jobless households, distinguishing between children (0-17) and adults (18-59). A household is jobless if no working age (18-59 years old) adult is employed (see Appendix A for a more detailed definition). Since labour is the primary source of income for the working age population, these indicators are usually interpreted as proxies for poverty. ${ }^{23}$

In Figure 13 I report the two indicators. ${ }^{24}$ I compare them to the labour income poverty rate computed in the ILFS and the relative and absolute poverty rate provided by Istat and based on consumption expenditure. For comparability I normalize the indicators such that the value in 2009 is set equal to 1. All the indicators jumped during the sovereign debt crisis. While the shares of people living in jobless households have started to slowly decline since 2014, poverty rates measured in the HBS persist at high levels; similar indications are drawn looking at the labour income poverty rate in the ILFS, even for 2018. The overall evidence suggests that the recent employment recovery is not translating into better economic conditions; behind this, the large increase of temporary and less stable jobs in the most recent years may have played only a marginal role in raising family labour income and consumption expenditure. Indeed, individuals classified as absolute poor not only are less likely to be employed than non-poor (only 40.0 per cent, rather than 57.0 per cent of 15-64 year-olds), but they are more represented among temporary and part-time contracts.

\section{Conclusions}

The aim of the paper is to build timely indicators for labour income inequality. Income inequality and poverty indicators are usually observed with one or two-year lag and, depending on the household income survey used, not even available with a yearly frequency. I take advantage of the available information in the ILFS to build up a measure of family and equivalised labour income and I focus on those families who are not likely to rely on pension income (the Reference Person is 15-64 years old and there are not retirees in the househoulds); these families are 60 per cent of overall Italian households, in which 70 per cent of the population lives. Then, I provide the Gini index and the labour income poverty rate computed on the basis of monthly equivalised labour income in the ILFS with a lag of only five-six months with respect to the reference period. The indicators are not meant to substitute standard measures of the income distribution - typically measured in

\footnotetext{
${ }^{23}$ This definition of jobless household is slightly different from the one used in subsection 5.1; however, observed patterns are broadly the same.

${ }^{24}$ For a detailed discussion about jobless households see Mocetti et al. (2011).
} 
household income surveys -, but to provide information on how much labour income inequality is arising due to variations in the employment rates.

The distribution of the income measure obtained in the ILFS looks pretty similar to the one observed in the SHIW (the more updated household income survey but run every two years), suggesting that, overall, the ILFS could provide reliable and robust information on this variable. Moreover, the Gini index of equivalised labour income in the ILFS traces the same pattern observed for the Gini index of the same income definition measured in the SHIW; in most recent years, their values are also very similar. When I compare the labour income poverty rate across different data sources (ILFS and SHIW), results are less precise and usually higher in the ILFS, mainly due to the different nature of the surveys: while the SHIW is run on a yearly basis (with a two-years frequency), the ILFS is run on a quarterly basis and reports the last month of pay. Thus, it is more likely to observe extreme low values in the ILFS and to obtain higher values of the poverty rate. However, dynamics are rather similar and show that the labour income poverty is still at high levels despite the labour market recovery started in 2014.

The ILFS, augmented with the information on the household income, offers also the opportunity to study more accurately the links between labour market dynamics and labour income distribution, which remains one of the main drivers of the dispersion of disposable income. Finally, the ILFS is representative at the region level, and it would be possible to compute the distributional indicators also at this level of aggregation; this avenue is left for future research. 


\section{References}

BańBura, M., Giannone, D., and L. Reichlin (2012). Nowcasting. In The Oxford Handbook of Economic Forecasting.

Böheim, R., and S. P. Jenkins (2006). A comparison of current and annual measures of income in the British Household Panel Survey, Journal of Official Statistics, 22(4), 733.

Bovini, G., and E. Viviano (2018). The Italian “employment-rich” recovery: a closer look, Bank of Italy's Occasional papers n. 461.

Brandolini, A. (2000). 'The Problematic Measurement of Income from Self-Employment': A Comment, Paper presented at the Seminar on Household Income Statistics organized by Eurostat, Luxembourg, 13-14 December 1999.

Brandolini, A., Cipollone, P., and P. Sestito (2002). Earnings dispersion, low pay and household poverty in Italy, 1977-1998 (pp. 225-264). In Cohen, D., Piketty, T. and G. Saint-Paul (ed.) The Economics of Rising Inequalities.

Brandolini, A. (2014). Il Grande Freddo. I bilanci delle famiglie italiane dopo la Grande Recessione, in C. Fusaro e A. Kreppel (a cura di), Politica in Italia. I fatti dell'anno e le interpretazioni. Edizione 2014, Bologna, Il Mulino.

Brandolini, A., and E. Viviano (2016). Behind and beyond the (head count) employment rate, Journal of the Royal Statistical Society: Series A (Statistics in Society), 179(3), 657681.

Brandolini, A., Gambacorta R. and A. Rosolia (2018). Inequality amid income stagnation: Italy over the last quarter of a century, Bank of Italy's Occasional Papers n. 442.

Ciani, E. and R. Torrini (2019). The geography of Italian income inequality: recent trends and the role of employment, Bank of Italy Occasional Paper n. 492.

European Parliament (2016). Poverty in the European Union: The crisis and its aftermath. EPRS European Parliamentary Research Service Author: Marie Lecerf Members' Research Service March 2016 - PE 579.099.

Fontaine, M., and J. Fourcot (2015). Nowcasting of poverty rate by microsimulation. Documents de Travail (INSEE), No F1506.

Galbraith, J. K., Choi, J., Halbach, B., Malinowska, A. and W. Zhang (2016). A Comparison of Major World Inequality Data Sets: LIS, OECD, EU-SILC, WDI, and EHII, in Cappellari, L., Polachek, S. W.and K. Tatsiramos (ed.) Income Inequality Around the World (Research in Labor Economics, Volume 44) Emerald Group Publishing Limited, pp. $1-48$. 
Gasior, K., and O. Rastrigina (2017). Nowcasting: timely indicators for monitoring risk of poverty in 2014-2016 (No. em7/17). EUROMOD at the Institute for Social and Economic Research.

Jappelli, T., and L. Pistaferri (2010). Does consumption inequality track income inequality in Italy?. Review of Economic Dynamics, 13(1), 133-153.

Jenkins, S. P., Brandolini, A., Micklewright, J., and B. Nolan (Eds.). (2012). The great recession and the distribution of household income. OUP Oxford.

Jenkins, S. P. (2009). Distributionally-sensitive inequality indices and the GB2 income distribution. Review of Income and Wealth, 55(2), 392-398.

Istat, (2014), I Nuovi Conti Nazionali in SEC 2010, Nota Informativa.

Mocetti, S., Olivieri E. and E. Viviano (2011). Italian households and labour market: structural characteristics and effects of the crisis, Stato e mercato, Società editrice il Mulino, Issue 2, 223-243.

Navicke, J., Rastrigina, O., and H. Sutherland (2014). Nowcasting indicators of poverty risk in the European Union: a microsimulation approach. Social Indicators Research, 119(1), 101-119.

Raitano, M. (2016). Income inequality in Europe since the crisis. Intereconomics, 51(2), 67-72.

Shorrocks, A. (1982). Inequality Decomposition by Factor Components, Econometrica, Vol. 50(1), 193-211.

Sestito, P. (2016), Audizione preliminare sulla delega recante norme relative al contrasto della povertà, al riordino delle prestazioni e al sistema degli interventi e dei servizi sociali (collegato alla legge di stabilità 2016), Camera dei deputati, Roma, 4 aprile 2016.

Vacas-Soriano, C., and E. Fernández-Macías (2018). Income Inequality in the Great Recession from an EU-wide Perspective. In CESifo Forum (Vol. 19, No. 2, pp. 9-18). München: ifo Institut-Leibniz-Institut für Wirtschaftsforschung an der Universität München. 


\section{Tables and Figures}

Table 1: Mincer equation of employees' hourly wage, ILFS 2009-2018

\begin{tabular}{|c|c|c|c|c|c|c|c|c|c|c|}
\hline $\begin{array}{l}\text { dependent } \\
\text { variable: } \\
\text { logarithm of } \\
\text { hourly wage }\end{array}$ & 2009 & 2010 & 2011 & 2012 & 2013 & 2014 & 2015 & 2016 & 2017 & 2018 \\
\hline \multirow[t]{2}{*}{ female } & $-0.084 * * *$ & $-0.089 * * *$ & $-0.089 * * *$ & $-0.080 * * *$ & $-0.076 * * *$ & $-0.071 * * *$ & $-0.071^{* * *}$ & $-0.065^{* * *}$ & $-0.076^{* * *}$ & $-0.072 * * *$ \\
\hline & $(0.004)$ & $(0.004)$ & $(0.004)$ & $(0.004)$ & $(0.004)$ & $(0.004)$ & $(0.004)$ & $(0.004)$ & $(0.003)$ & $(0.004)$ \\
\hline \multirow[t]{2}{*}{ female*married } & $-0.037 * * *$ & $-0.039 * * *$ & $-0.036^{* * *}$ & $-0.034 * * *$ & $-0.045 * * *$ & $-0.035 * * *$ & $-0.034 * * *$ & $-0.033^{* * *} *$ & $-0.031 * * *$ & $-0.031 * * *$ \\
\hline & $(0.004)$ & $(0.004)$ & $(0.004)$ & $(0.004)$ & $(0.004)$ & $(0.004)$ & $(0.004)$ & $(0.004)$ & $(0.004)$ & $(0.004)$ \\
\hline \multirow[t]{2}{*}{ female*n children } & 0.000 & $0.005^{* *}$ & $0.005 * *$ & $0.004 * *$ & $0.007 * * *$ & $0.004 *$ & $0.008 * * *$ & $0.007 * * *$ & $0.008 * * *$ & $0.010 * * *$ \\
\hline & $(0.002)$ & $(0.002)$ & $(0.002)$ & $(0.002)$ & $(0.002)$ & $(0.002)$ & $(0.002)$ & $(0.002)$ & $(0.002)$ & $(0.002)$ \\
\hline \multirow[t]{2}{*}{$25-34$} & $0.126 * * *$ & $0.125 * * *$ & $0.127 * * *$ & $0.129 * * *$ & $0.125 * * *$ & $0.136 * * *$ & $0.134 * * *$ & $0.128 * * *$ & $0.123 * * *$ & $0.125 * * *$ \\
\hline & $(0.004)$ & $(0.004)$ & $(0.004)$ & $(0.005)$ & $(0.005)$ & $(0.005)$ & $(0.005)$ & $(0.005)$ & $(0.005)$ & $(0.005)$ \\
\hline \multirow[t]{2}{*}{$35-44$} & $0.228 * * *$ & $0.219 * * *$ & $0.220 * * *$ & $0.231 * * *$ & $0.227 * * *$ & $0.244 * * *$ & $0.241 * * *$ & 0.237 *** & $0.230 * * *$ & $0.229 * * *$ \\
\hline & $(0.004)$ & $(0.004)$ & $(0.004)$ & $(0.005)$ & $(0.005)$ & $(0.005)$ & $(0.005)$ & $(0.005)$ & $(0.005)$ & $(0.005)$ \\
\hline \multirow[t]{2}{*}{$45-54$} & $0.281 * * *$ & $0.275^{* * *}$ & $0.275^{* * *}$ & $0.284 * * *$ & $0.275^{* * *}$ & $0.296 * * *$ & $0.287 * * *$ & $0.286^{* * *}$ & $0.283^{* * *}$ & $0.272 * * *$ \\
\hline & $(0.004)$ & $(0.005)$ & $(0.004)$ & $(0.005)$ & $(0.005)$ & $(0.005)$ & $(0.005)$ & $(0.005)$ & $(0.005)$ & $(0.005)$ \\
\hline \multirow[t]{2}{*}{$55-64$} & $0.336 * * *$ & $0.329 * * *$ & $0.324 * * *$ & $0.331 * * *$ & $0.329 * * *$ & $0.350 * * *$ & $0.339 * * *$ & $0.334 * * *$ & $0.321 * * *$ & $0.312 * * *$ \\
\hline & $(0.005)$ & $(0.005)$ & $(0.005)$ & $(0.005)$ & $(0.006)$ & $(0.005)$ & $(0.005)$ & $(0.005)$ & $(0.005)$ & $(0.005)$ \\
\hline \multirow[t]{2}{*}{$64+$} & $0.333 * * *$ & $0.341 * * *$ & $0.311 * * *$ & $0.336 * * *$ & $0.322 * * *$ & $0.334 * * *$ & $0.291 * * *$ & $0.292 * * *$ & $0.324 * * *$ & $0.323 * * *$ \\
\hline & $(0.014)$ & $(0.015)$ & $(0.014)$ & $(0.014)$ & $(0.013)$ & $(0.013)$ & $(0.012)$ & $(0.011)$ & $(0.010)$ & $(0.009)$ \\
\hline \multirow[t]{2}{*}{1 child } & -0.001 & $-0.006 * *$ & $-0.012 * * *$ & -0.003 & -0.001 & -0.004 & -0.004 & $-0.006^{* *}$ & $-0.008 * * *$ & $-0.010 * * *$ \\
\hline & $(0.003)$ & $(0.003)$ & $(0.003)$ & $(0.003)$ & $(0.003)$ & (0.003) & $(0.003)$ & $(0.003)$ & $(0.003)$ & (0.003) \\
\hline \multirow[t]{2}{*}{2 children } & $0.013 * * *$ & $0.006^{*}$ & 0.002 & $0.009 * * *$ & $0.014 * * *$ & $0.011 * * *$ & $0.010^{* * *}$ & $0.010^{* * * *}$ & 0.004 & 0.005 \\
\hline & $(0.003)$ & $(0.003)$ & $(0.003)$ & $(0.003)$ & $(0.003)$ & $(0.003)$ & $(0.003)$ & $(0.003)$ & (0.003) & $(0.003)$ \\
\hline \multirow[t]{2}{*}{3 children } & $0.021 * * *$ & $0.010^{* *}$ & $0.012 * *$ & $0.018 * * *$ & $0.014 * * *$ & $0.023 * * *$ & 0.003 & $0.014 * * *$ & $0.014 * * *$ & -0.006 \\
\hline & $(0.005)$ & $(0.005)$ & $(0.005)$ & $(0.005)$ & $(0.005)$ & $(0.005)$ & $(0.005)$ & $(0.005)$ & $(0.005)$ & $(0.005)$ \\
\hline \multirow[t]{2}{*}{4 or more children } & $0.025 * * *$ & 0.012 & -0.001 & 0.006 & $0.018 *$ & 0.013 & -0.005 & 0.007 & 0.010 & -0.006 \\
\hline & $(0.009)$ & (0.009) & (0.009) & $(0.010)$ & $(0.010)$ & $(0.010)$ & (0.010) & (0.010) & $(0.010)$ & $(0.010)$ \\
\hline \multirow[t]{2}{*}{ married } & $0.101 * * *$ & $0.106 * * *$ & $0.101 * * *$ & $0.092 * * *$ & $0.100 * * *$ & $0.091 * * *$ & $0.089 * * *$ & $0.084 * * *$ & $0.087 * * *$ & $0.084 * * *$ \\
\hline & $(0.003)$ & $(0.003)$ & $(0.003)$ & $(0.003)$ & $(0.003)$ & $(0.003)$ & $(0.003)$ & $(0.003)$ & $(0.003)$ & $(0.003)$ \\
\hline \multirow[t]{2}{*}{ foreign } & $-0.151 * * *$ & $-0.159 * * *$ & $-0.152 * * *$ & $-0.145^{* * *}$ & $-0.145 * * *$ & $-0.150 * * *$ & $-0.162 * * *$ & $-0.150 * * *$ & $-0.150 * * *$ & $-0.145^{* * *}$ \\
\hline & $(0.004)$ & $(0.003)$ & $(0.003)$ & $(0.003)$ & $(0.003)$ & $(0.003)$ & $(0.003)$ & $(0.003)$ & $(0.003)$ & $(0.003)$ \\
\hline \multirow[t]{2}{*}{$\begin{array}{l}\text { lower secondary } \\
\text { education }\end{array}$} & $0.081 * * *$ & $0.075 * * *$ & $0.050 * * *$ & $0.055^{* * *}$ & $0.065^{* * *}$ & $0.070 * * *$ & $0.061 * * *$ & $0.067 * * *$ & $0.063 * * *$ & $0.067 * * *$ \\
\hline & $(0.004)$ & $(0.005)$ & $(0.005)$ & $(0.005)$ & $(0.005)$ & $(0.005)$ & $(0.006)$ & $(0.006)$ & $(0.006)$ & $(0.006)$ \\
\hline \multirow[t]{2}{*}{$\begin{array}{l}\text { upper secondary } \\
\text { education }\end{array}$} & $0.205^{* * *}$ & $0.198 * * *$ & $0.175^{* * *}$ & $0.175^{* * *}$ & $0.181 * * *$ & $0.180 * * *$ & $0.171^{* * *} *$ & $0.180^{* * *} *$ & $0.173 * * *$ & $0.174 * * *$ \\
\hline & $(0.004)$ & $(0.005)$ & $(0.005)$ & $(0.005)$ & $(0.005)$ & $(0.005)$ & $(0.006)$ & $(0.006)$ & $(0.006)$ & $(0.006)$ \\
\hline \multirow[t]{2}{*}{ tertiary education } & $0.436 * * *$ & $0.423 * * *$ & $0.393 * * *$ & $0.374 * * *$ & $0.388^{* * *}$ & $0.381 * * *$ & $0.366^{* * *}$ & $0.378 * * *$ & $0.355 * * *$ & $0.354 * * *$ \\
\hline & $(0.005)$ & $(0.005)$ & $(0.005)$ & $(0.006)$ & $(0.006)$ & $(0.006)$ & $(0.006)$ & $(0.006)$ & $(0.006)$ & $(0.006)$ \\
\hline \multirow[t]{2}{*}{ full-time job } & $-0.042 * * *$ & $-0.047 * * *$ & $-0.049 * * *$ & $-0.051 * * *$ & $-0.066^{* * *}$ & $-0.058 * * *$ & $-0.068^{* * * *}$ & $-0.064 * * *$ & $-0.052 * * *$ & $-0.055 * * *$ \\
\hline & $(0.003)$ & $(0.003)$ & $(0.003)$ & $(0.003)$ & $(0.003)$ & $(0.003)$ & $(0.003)$ & $(0.003)$ & $(0.003)$ & $(0.003)$ \\
\hline \multirow[t]{2}{*}{ Constant } & $1.403 * * *$ & $1.410 * * *$ & $1.445^{* * *}$ & $1.451 * * *$ & $1.488 * * *$ & $1.495 * * *$ & $1.533 * * *$ & $1.563 * * *$ & $1.582 * * *$ & $1.570 * * *$ \\
\hline & $(0.010)$ & $(0.010)$ & $(0.010)$ & $(0.011)$ & $(0.011)$ & $(0.011)$ & $(0.011)$ & $(0.011)$ & $(0.011)$ & $(0.011)$ \\
\hline Province dummies & YES & YES & YES & YES & YES & YES & YES & YES & YES & \\
\hline Sectoral dummies & YES & YES & YES & YES & YES & YES & YES & YES & YES & \\
\hline Observations & 154344 & 154778 & 152635 & 139991 & 138656 & 136560 & 136566 & 137933 & 140348 & 131848 \\
\hline R-squared & 0.307 & 0.310 & 0.320 & 0.296 & 0.292 & 0.302 & 0.301 & 0.315 & 0.304 & 0.303 \\
\hline
\end{tabular}

Source: ILFS, sample weights are used. Standard errors in parentheses. Coefficients are statistically significant with probability: $* * * \mathrm{p}<0.01$, $* * \mathrm{p}<0.05, * \mathrm{p}<0.1$ 
Table 2: Mincer equation of workers' hourly wage, SHIW 2008-2016

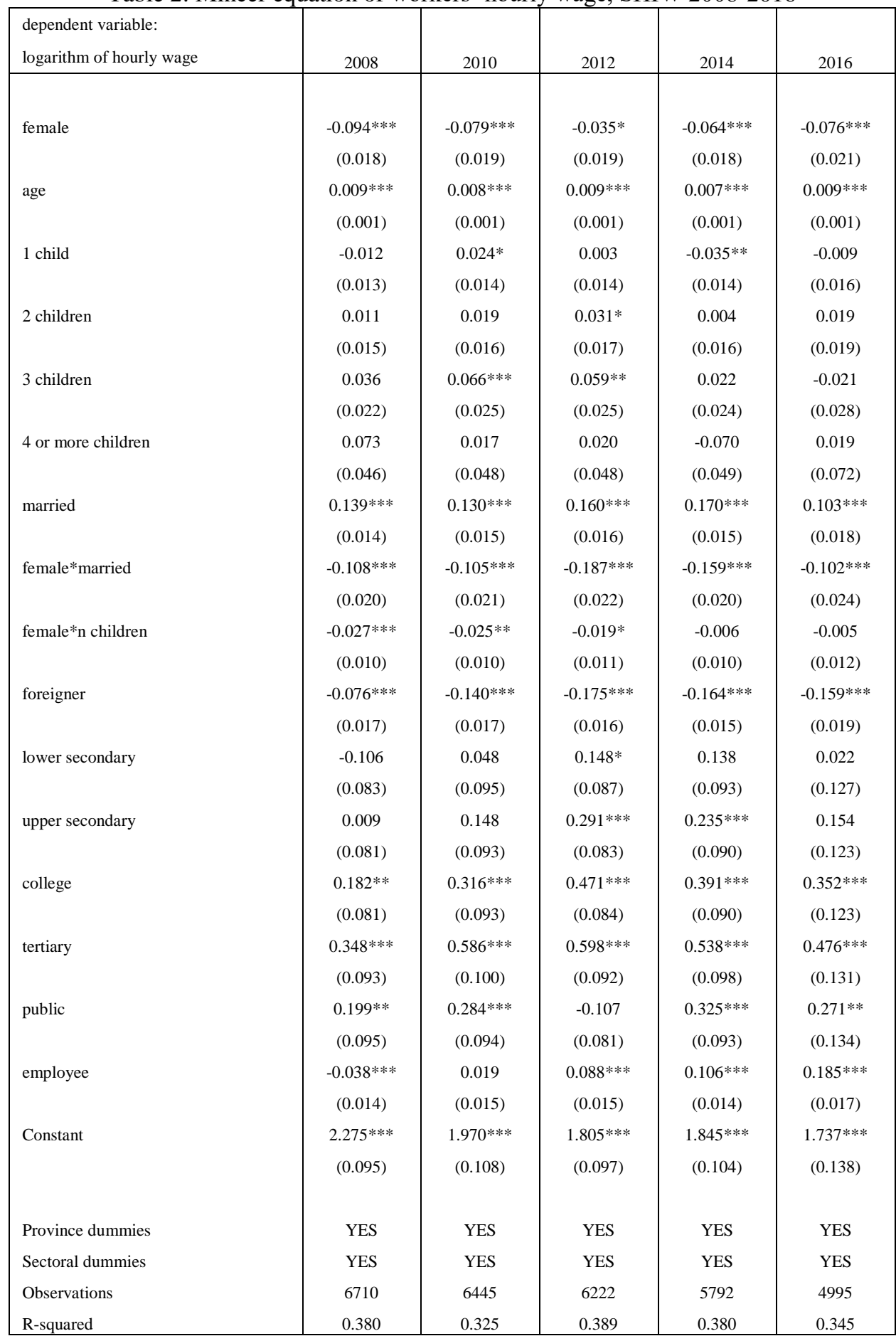

Source: SHIW, sample weights are used. Standard errors in parentheses. Coefficients are statistically significant with probability: $* * *$ $\mathrm{p}<0.01, * * \mathrm{p}<0.05, * \mathrm{p}<0.1$. 
Table 3: Decomposition of Gini index on equivalised income by income source, SHIW 2016

\begin{tabular}{lccccc}
\cline { 2 - 6 } & Share & $\begin{array}{c}\text { Gini } \\
\text { Coefficient }\end{array}$ & $\begin{array}{c}\text { Gini } \\
\text { Correlation }\end{array}$ & Contribution & $\begin{array}{c}\text { Contribution } \\
(\%)\end{array}$ \\
\cline { 2 - 6 } Variable & $S_{k}$ & $G_{k}$ & $R_{k}$ & $S_{k} * G_{k} * R_{k}$ & $S_{k} * G_{k} * R_{k} / G$ \\
labour & 0.557 & 0.520 & 0.648 & 0.188 & 0.569 \\
transfers & 0.251 & 0.719 & 0.406 & 0.073 & 0.219 \\
capital & 0.192 & 0.514 & 0.742 & 0.073 & 0.219 \\
\multicolumn{1}{c}{ TOTAL } & 1 & 0.334 & 1 & 0.334 & 1 \\
\hline
\end{tabular}

Source: SHIW, sample weights are used. Share $S_{k}$ is is the component $k$ 's share of total income; $G_{k}$ is the Gini index for a component $k$; $R_{k}$ is the Gini correlation between income component and the total income. Product $S_{k} * G_{k} * R_{k}$ is the absolute contribution of $k$ component to income inequality. For positive values of $R_{k}$, the necessary condition for inequality to increase as a result of a growing concentration within component $k$ is $G_{k}$ is greater than $G$. The Table shows that increased labour income inequality is associated to higher total income inequality; labour income inequality contributes to income inequality by 57 per cent.

Table 4: Decomposition of Gini index of equivalised labour income

\begin{tabular}{cccc}
\hline Year & $G$ & $(1-e)$ & $e * G_{e}$ \\
\hline 2009 & 33.6 & 7.8 & 25.9 \\
2010 & 34.3 & 8.4 & 25.9 \\
2011 & 34.3 & 8.7 & 25.6 \\
2012 & 35.2 & 9.5 & 25.8 \\
2013 & 36.6 & 10.8 & 25.8 \\
2014 & 36.8 & 11.2 & 25.6 \\
2015 & 36.4 & 11.0 & 25.5 \\
2016 & 36.1 & 10.6 & 25.5 \\
2017 & 35.6 & 10.3 & 25.3 \\
2018 & 35.4 & 10.0 & 25.4 \\
Delta $2009-2014$ & 3.1 & 3.4 & -0.3 \\
Delta $2014-2018$ & -1.4 & -1.2 & -0.2 \\
\hline
\end{tabular}

Source: ILFS, sample weights are used. I consider households with no retirees and in which the reference person is 15-64 years. The variable $e$ is the share of individuals leaving in households with positive values of labour income; $G_{e}$ is the Gini index computed on equivalised labour income of those who live in households with positive values of labour income; $G$ is the Gini index computed on equivalised labour income, including those who have zero equivalised labour income. The decomposition is based on the formula: $G=$ $(1-e)+e^{*} G_{e}$ (see Appendix A). 
Figure 1: Gini index on equivalised disposable income

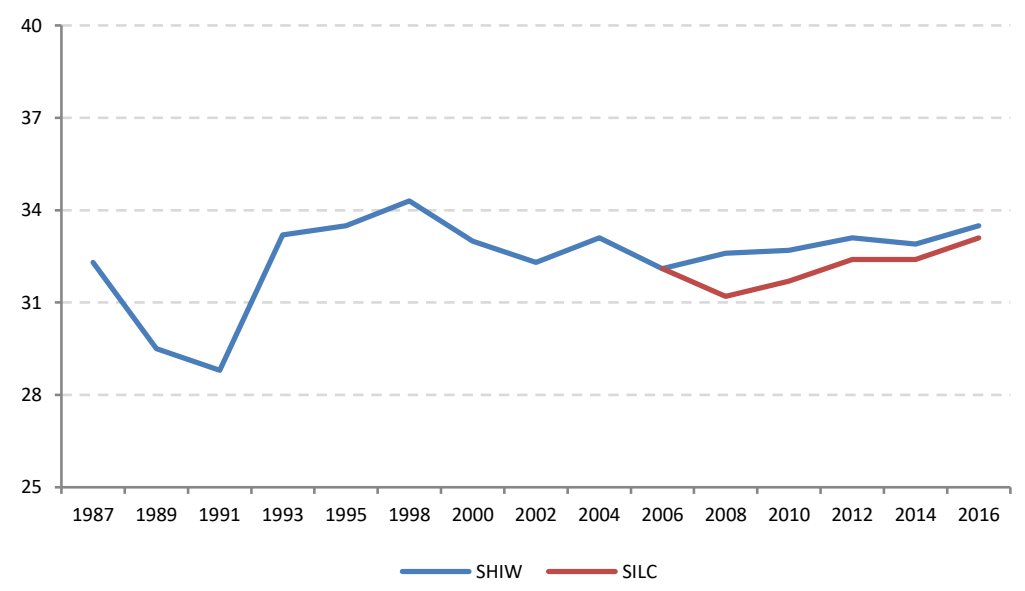

Source: EU-SILC and SHIW, sample weights are used. Equivalised income is equal to family income divided by the OECD-modified equivalence scale. As for the EU-SILC, I consider only those years in which the SHIW is available.

Figure 2: Equivalised labour income as share of equivalised disposable income

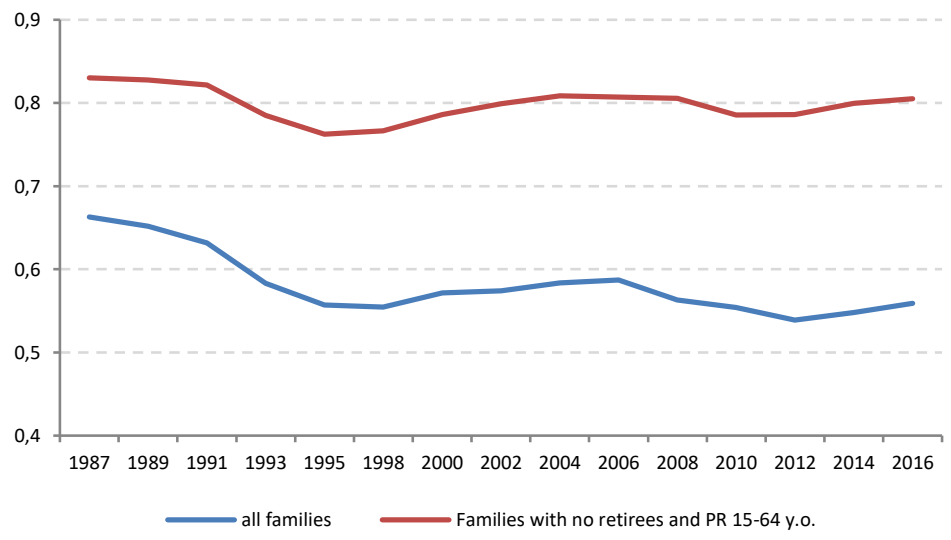

Source: SHIW, sample weights are used. Equivalised income is equal to family income divided by the OECD-modified equivalence scale; equivalised labour income is analogously defined. 
Figure 3: Gini index on equivalised disposable income and on equivalised labour income
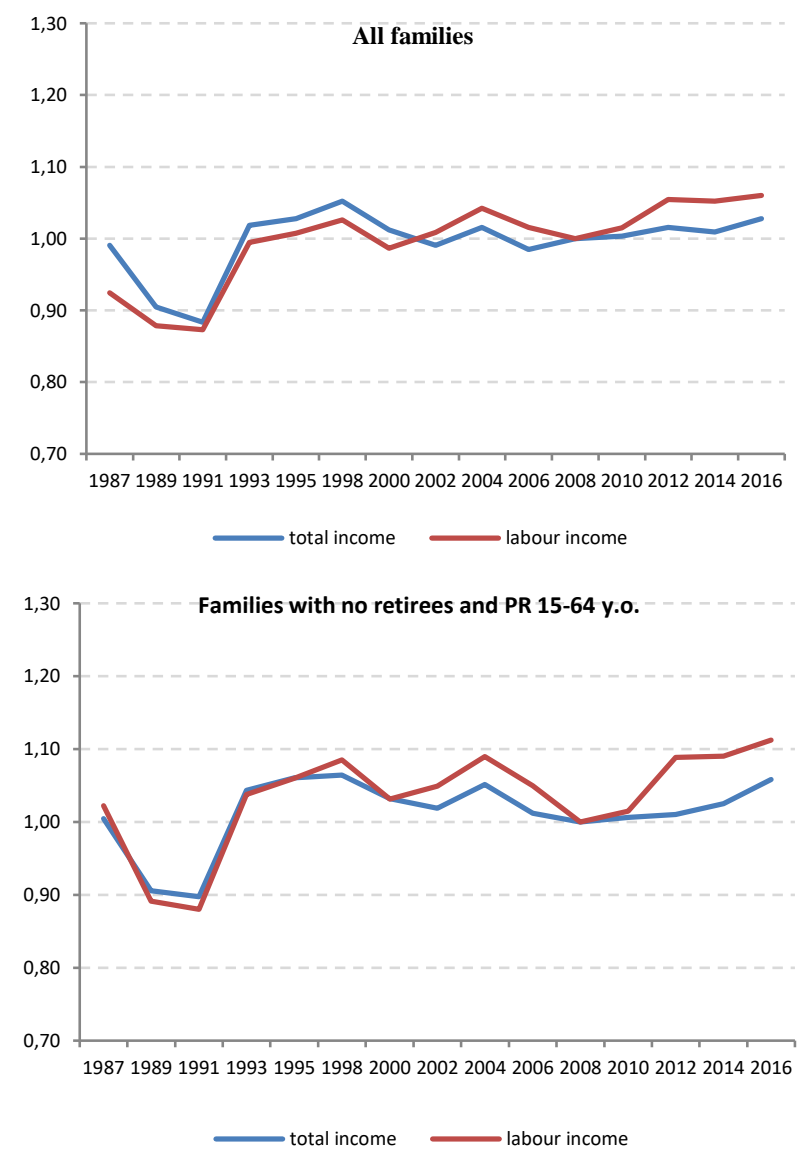

Source: SHIW, sample weights are used. Equivalised income is equal to family income divided by the OECD-modified equivalence scale; equivalised labour income is analogously defined. Indices are normalized with respect to the 2008 value. 
Figure 4: Gini index on equivalised monthly and yearly labour income in the SHIW, most recent years

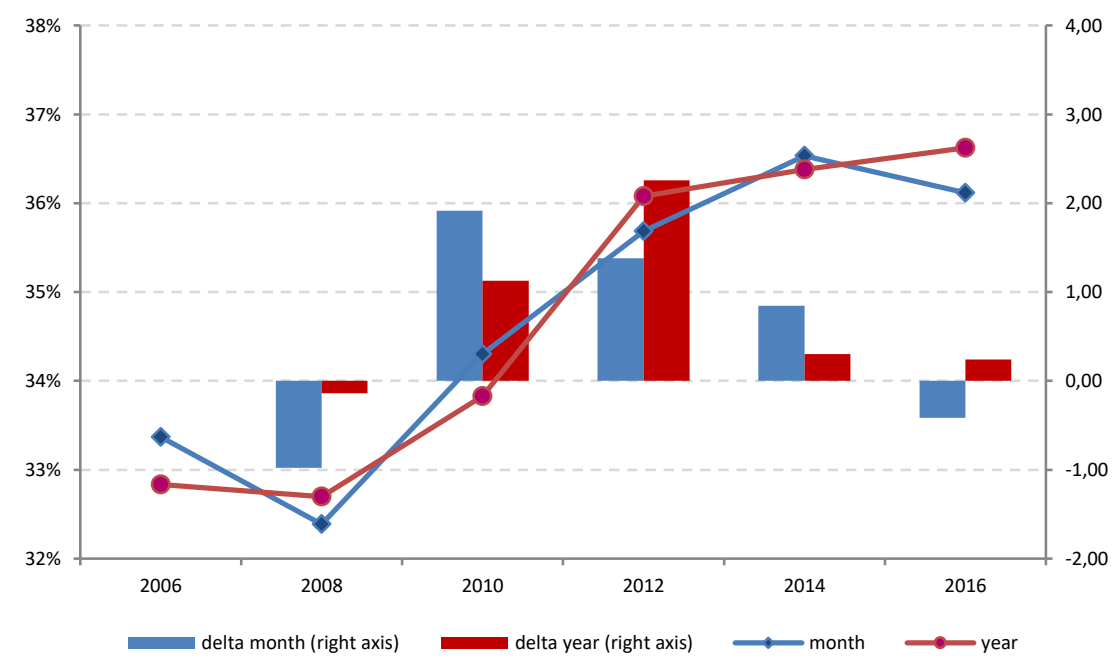

Source: SHIW, sample weights are used. Equivalised labour income is equal to family labour income divided by the OECD-modified equivalence scale. "month" refers to monthly equivalised labour income, obtained as the ratio between yearly labour income and the number of months worked, then aggregated at family level; "year" refers to yearly equivalised labour income; "delta month" is the difference between the Gini index on monthly equivalised labour income computed in a given year (i.e. 2010) and that in the two-year before (i.e. 2008); "delta year" is analogously defined.

Figure 5: Monthly wage distribution in the ILFS and in the SHIW by year

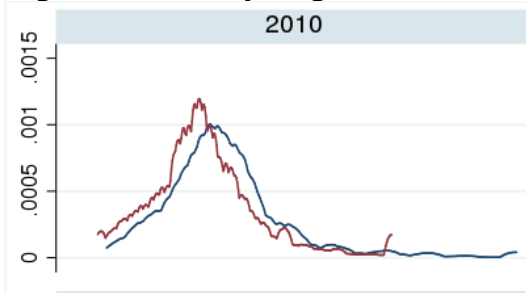

2012
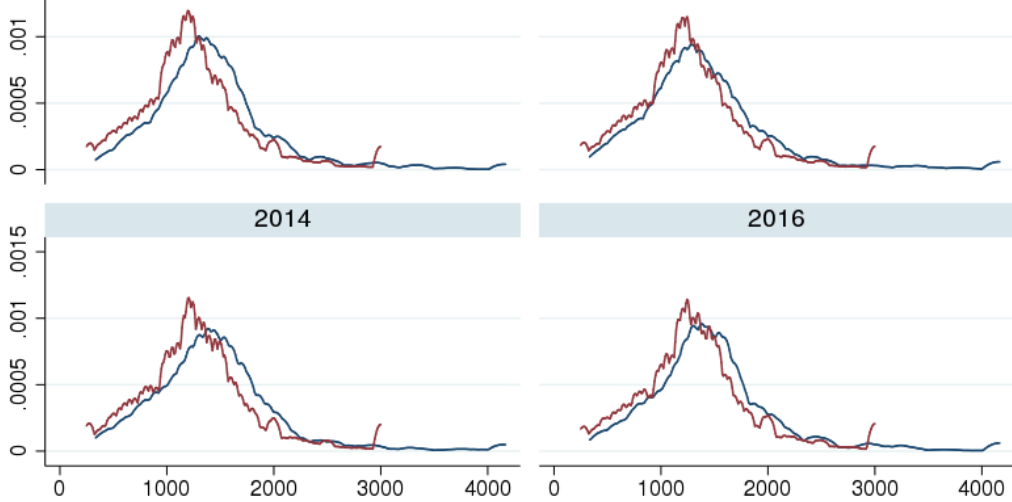

2016

SHIW
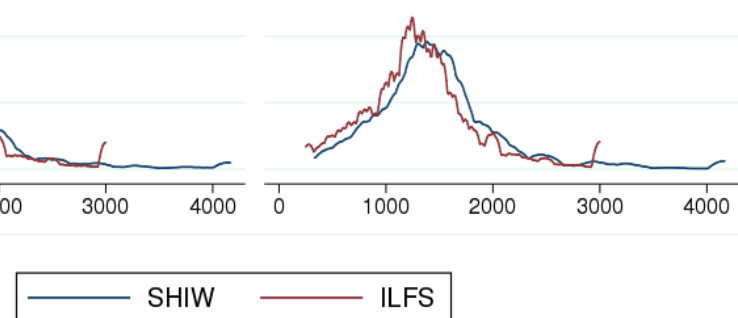

Source: ILFS and SHIW, sample weights are used. The ILFS wage is the net regular salary earned one month before (no 13th or 14th month's salary), excluding those extra-payments that are not commonly included in the monthly pay. The salary is reported in bin of 10 euros for amounts between 250 and 3000 euros; for lower and higher levels, there are two categories, respectively: 250- euros and 3000+ euros. The SHIW monthly wage is obtained as the ratio between annual earnings and months worked in the reference year (for employees only). Extremes values for the SHIW variable are winsorized at level 1 and 99 per cent levels for each year. 
Figure 6: Monthly self-employed income in the ILFS (obtained by imputation) and in the SHIW
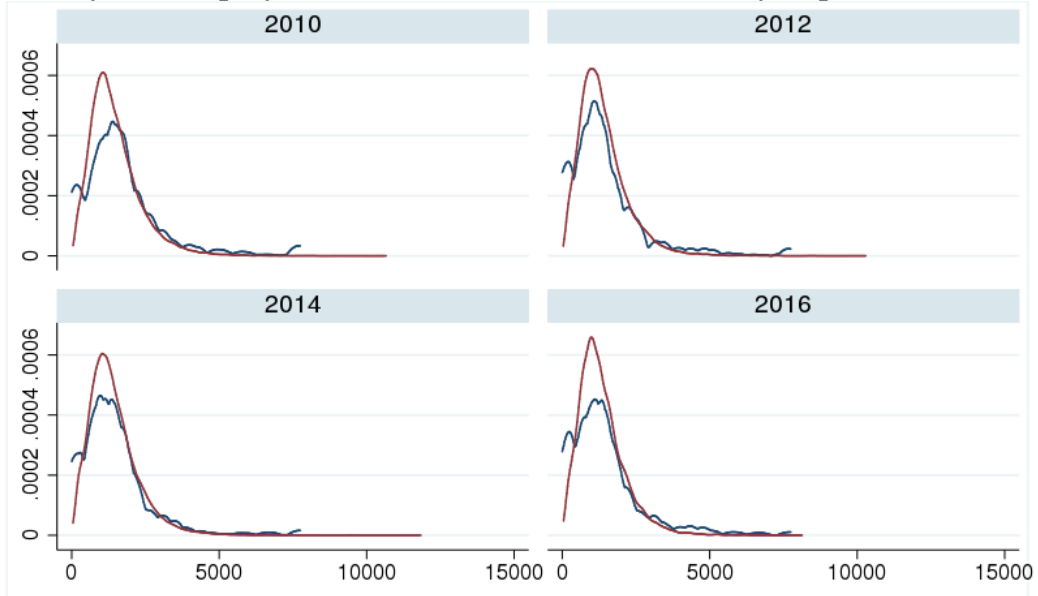

$$
\begin{array}{r}
\mathrm{x} \\
-\mathrm{SHIW} \longrightarrow \text { ILFS }
\end{array}
$$

Source: ILFS and SHIW, sample weights are used. The ILFS self-employed income has been imputed as described in Section 3, by estimating a Mincerian equation of hourly wage on observable individual and family characteristics. The SHIW self-employed income is obtained as the ratio between annual income and months worked in the reference year (for self-employed only). Extremes values are winsorized at level 1 and 99 per cent levels for each year.

Figure 7: Monthly equivalised labour income in the ILFS and in the SHIW

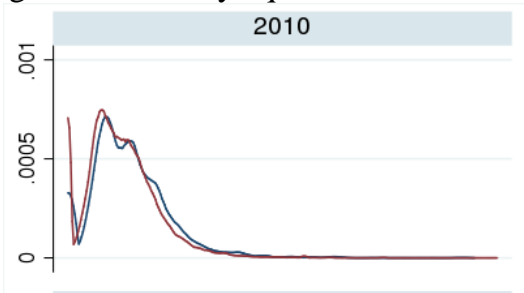

2014

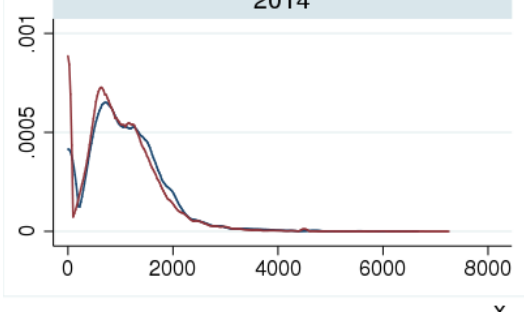

$\mathrm{X}$

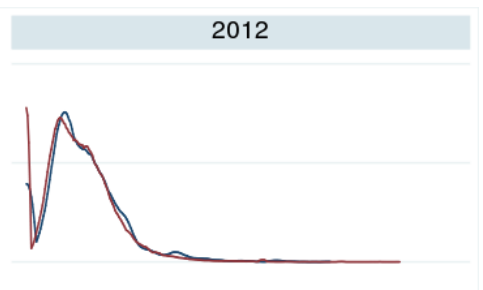

2016

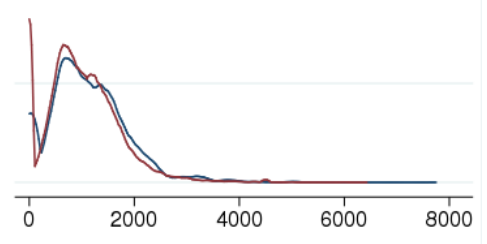

SHIW ILFS

Source: ILFS and SHIW, sample weights are used. The ILFS monthly equivalised labour income is obtained by aggregating labour incomes at household level, divided by the OECD-modified equivalence scale to take into account economies of scale within the household. The SHIW monthly equivalised labour income is analogously defined. Extremes values are winsorized at level 1 and 99 per cent levels for each year. 
Figure 8: Comparison of Gini index computed on monthly labour income in the ILFS and in the SHIW

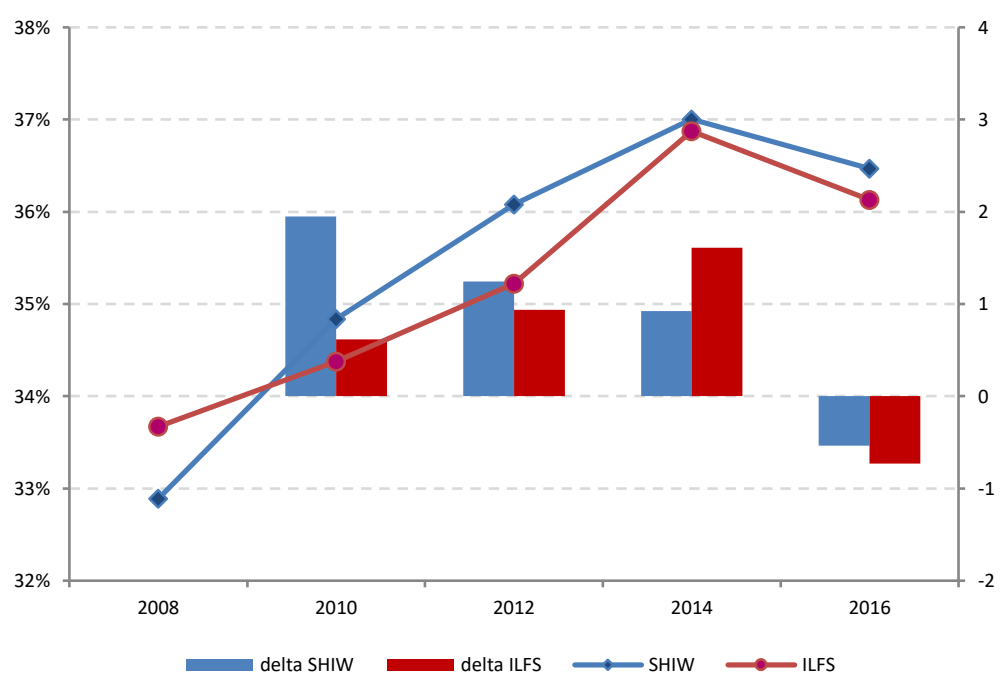

Source: ILFS and SHIW, sample weights are used. Gini index computed on equivalised labour incomes. I consider only those years in which both surveys are available. "delta SHIW"(right axis) is the difference between the Gini index computed in a given year (i.e. 2010) and that in the two-year before (i.e. 2008); "delta ILFS" is analogously defined. "delta ILFS" in 2010 is the difference between the Gini index in 2010 and that in 2009 since the value for 2008 is not available. Gini index computed in the ILFS in 2008 refers to 2009 incomes.

Figure 9: Comparison of labour income poverty rate in the ILFS and in the SHIW

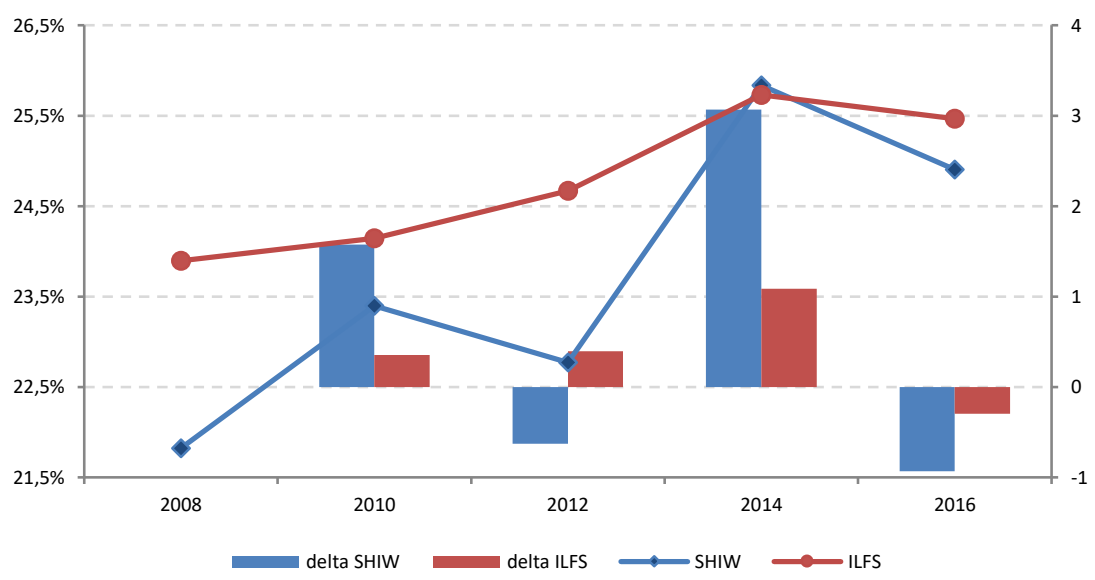

Source: ILFS and SHIW, sample weights are used. Labour Income Poverty Rate (LIPR): share of individuals with equivalised monthly labour income lower than the 60 per cent of the national median value. I consider only those years in which both surveys are available. "delta SHIW" (right axis) is the difference between the LIPR computed in a given year (i.e. 2010) and that in the two-year before (i.e. 2008); "delta ILFS" is analogously defined. "delta ILFS" in 2010 is the difference between the corresponding LIPR in 2010 and that in 2009 since the value for 2008 is not available. LIPR computed in the ILFS in 2008 refers to 2009 incomes. 
Figure 10: Comparison of Gini index computed on monthly labour income in the LFS, in the LFS with correction for censoring and in the SHIW

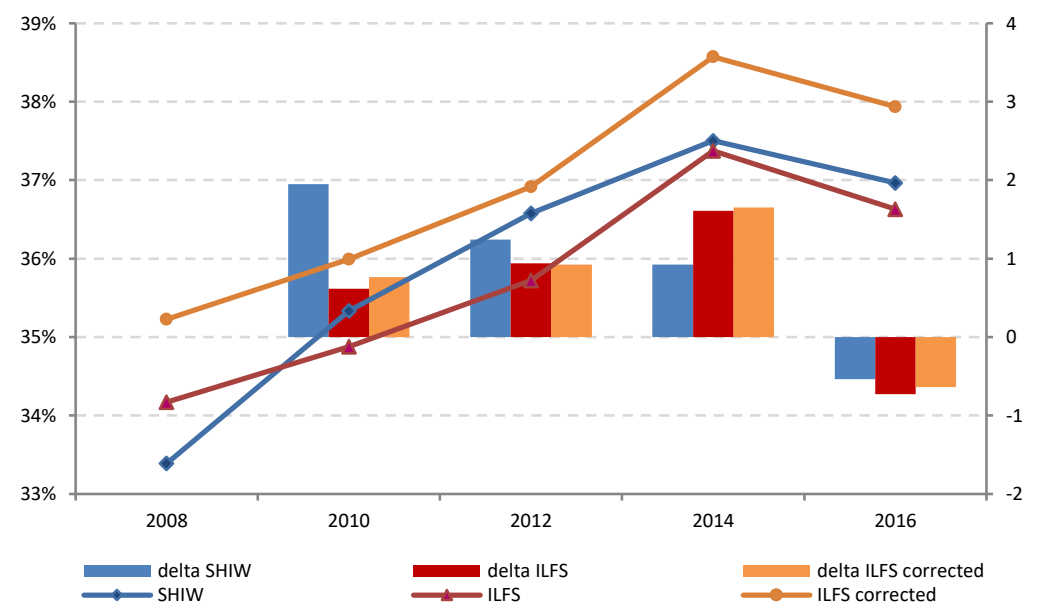

Source: ILFS and SHIW, sample weights are used. Gini index computed on equivalised labour incomes. Monthly wage in the ILFS is corrected for censoring: I assume that employees' monthly wages censored at 250 euros are distributed according to a uniform distribution [0;250] and assign them the mean value, i.e. 125 rather than 250 . For values censored at 3000 euros, I assume that monthly wages are distributed according to a Pareto distribution. "delta SHIW" (right axis) is the difference between the Gini index computed in a given year (i.e. 2010) and that in the two-year before (i.e. 2008); "delta ILFS" and "delta ILFS corrected" are analogously defined. "delta ILFS" and "delta ILFS corrected" in 2010 are the difference between the respective Gini index in 2010 and that in 2009 since the value for 2008 is not available. Gini index computed in the ILFS in 2008 refers to 2009 incomes.

Figure 11: Comparison of Gini index computed on monthly labour income in the LFS, in the SHIW and in the SHIW with censored monthly wage

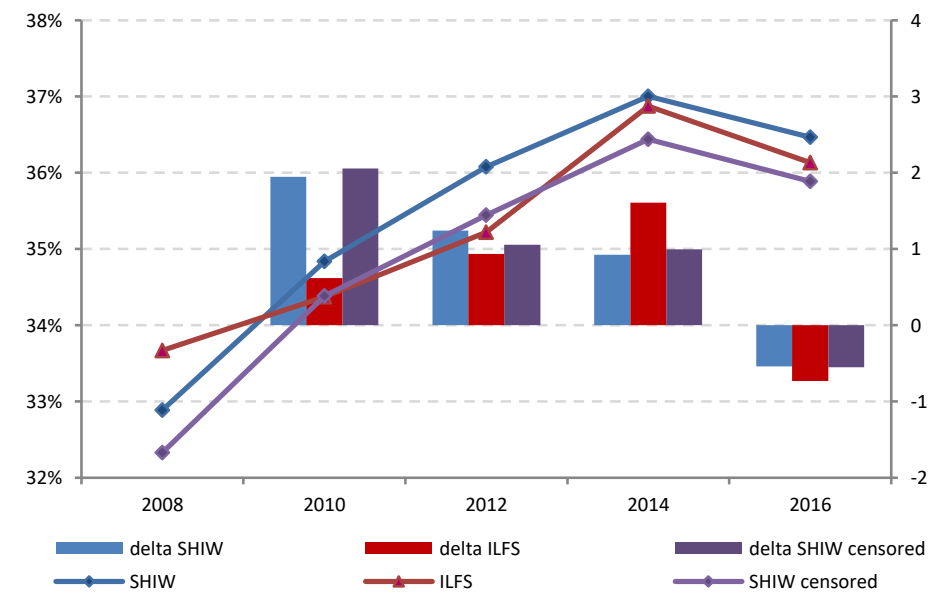

Source: ILFS and SHIW, sample weights are used. Gini index computed on equivalised monthly labour incomes. Monthly wage in the SHIW is censored censored from below (at 250) and from above (at 3000), analogously as in the ILFS. "delta SHIW" (right axis) is the difference between the Gini index computed in a given year (i.e. 2010) and that in the two-year before (i.e. 2008); "delta ILFS" and "delta SHIW censored" are analogously defined. "delta ILFS" in 2010 is the difference between the respective Gini index in 2010 and that in 2009 since the value for 2008 is not available. Gini index computed in the ILFS in 2008 refers to 2009 incomes. 
Figure 12: The Gini index on monthly equivalised labour income in the ILFS and in the SHIW, latest years

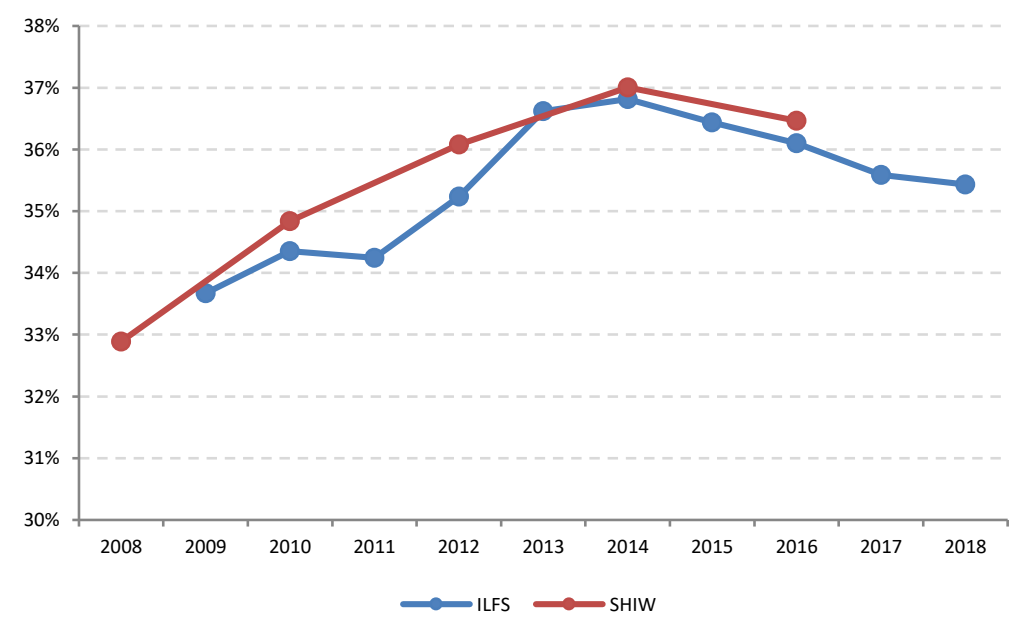

Source: ILFS and SHIW, sample weights are used.

Figure 13: Different measures of poverty

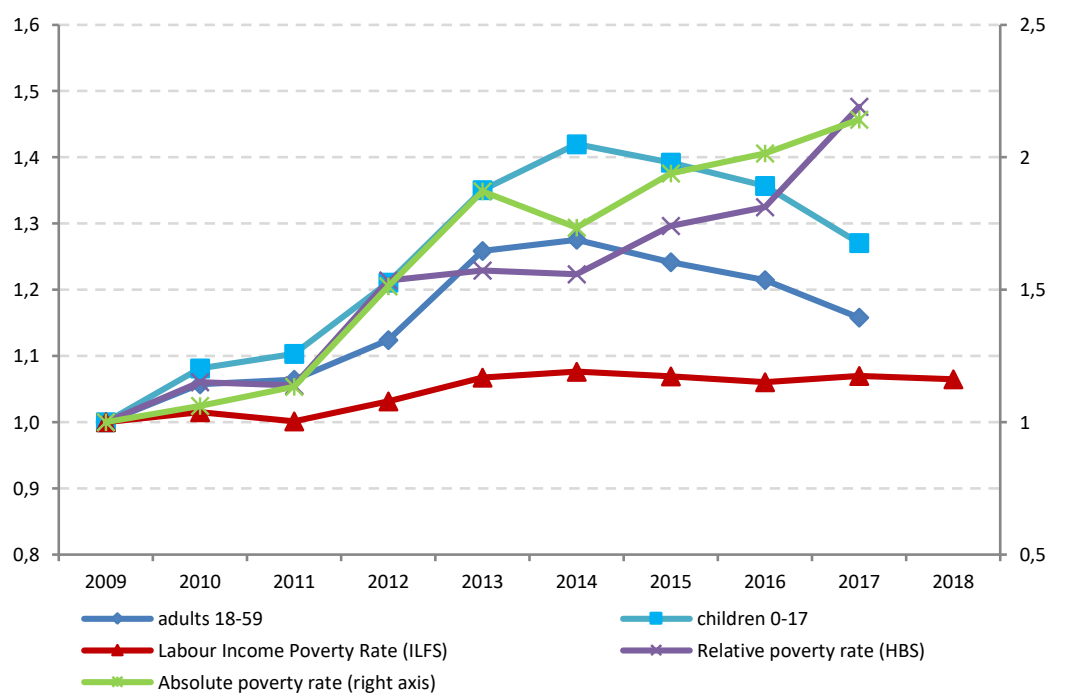

Source: ILFS and HBS, sample weights are used. Adults 18-59 and children 0-17 are the share of people living in jobless households, distinguishing by age. Labour Income Poverty Rate (ILFS) is the share of individuals with equivalised monthly labour income lower than the 60 per cent of the national median value computed in the ILFS. Relative poverty rate (HBS) is the share of individuals whose consumption expenditure is lower than the relative poverty line, measured in the HBS. Absolute poverty rate (HBS) is the share of individuals whose consumption expenditure is lower than the absolute poverty line, measured in the HBS. 


\section{Appendix A: Definitions}

\section{Inequality and poverty: two related but different concepts}

Inequality measures how an economic variable (e.g. consumption, income, wealth) is distributed across individuals belonging to a specific group (that could be, for example, a given country, or a confederation of States or the world itself). Poverty refers to economic deprivation or lack of resources. Depending on the reference point according to which deprivation is measured, there are two different definitions of poverty. One is relative poverty, according to which deprivation is measured with respect to a certain value defined within the reference population (e.g. the median of the income distribution). The other definition is that of absolute poverty, where deprivation refers to the lack of resources considered as minimum socially acceptable for a decent life. While relative poverty changes with the mean values of the reference population, absolute poverty does not.

Inequality and poverty are usually considered measures of economic distress; however, even if the indicators are computed referring to the same economic variable, they do not necessarily go hand in hand, especially when we refer to absolute poverty. The following figures illustrate how such concepts differ. Figure A1 pictures the situation in which two distributions share the same incidence of poverty but different level of inequality: the dashed red line differs from the original one as for the top of the distribution, having a higher number of richer individuals and a lower number of medium income individuals. The area on the left of the poverty threshold, representing the share of the poor, is the same for the two distributions. In Figure A2 the dashed red line is simply a translation of the original distribution, and they share the same level of inequality. However, the area on the left of the poverty threshold is larger under the dashed red line than with respect to the blue one, pointing out that the number of the poor (and the intensity of poverty) is higher.

Figure A1: Distributions with same incidence of poverty but different inequality levels

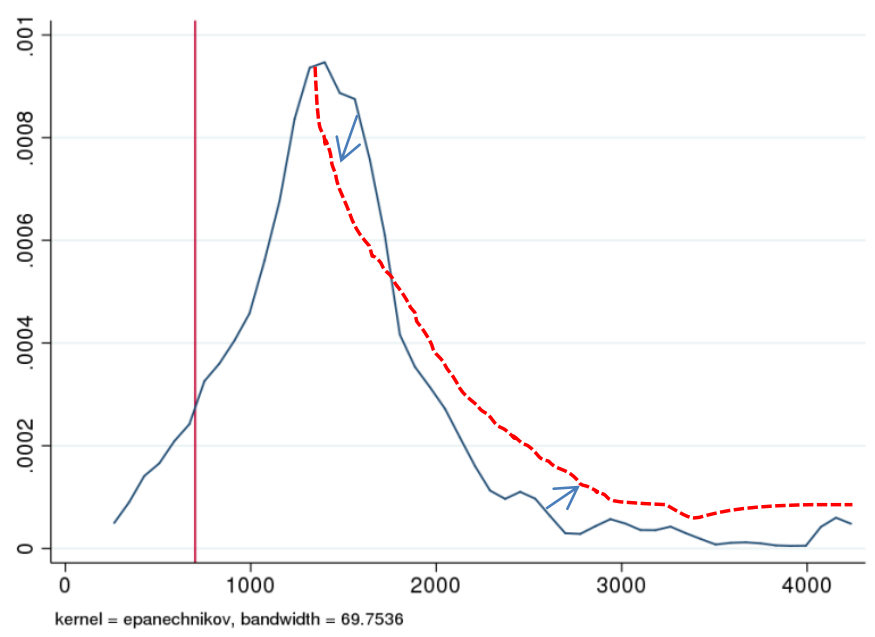


Note: The vertical line represents a given poverty threshold. The poverty rate is the area below the blue line on the left of the poverty threshold. The blue distribution displays a lower level of inequality than the red dashed distribution, despite they share the same share of poor individuals.

Figure A2: Distributions with same inequality level but different incidence of poverty

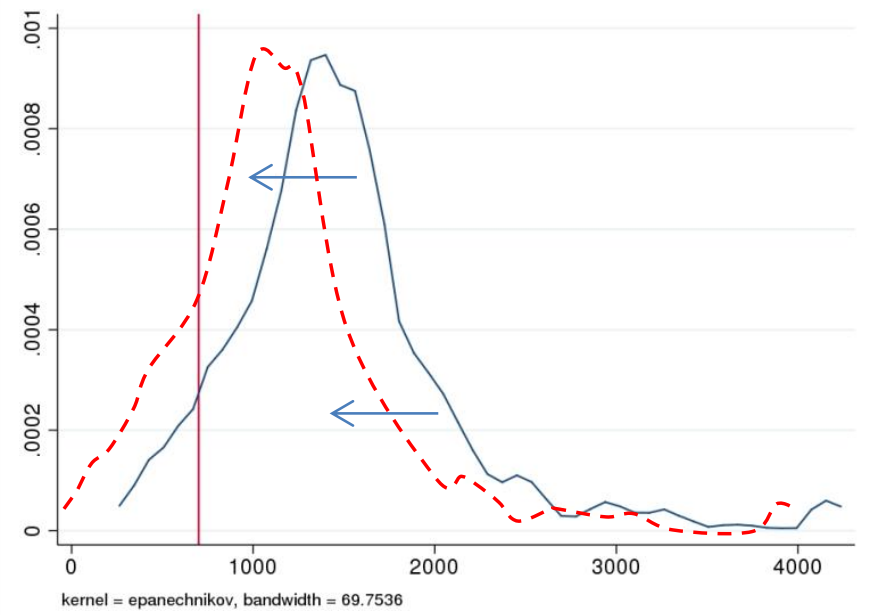

Note: The vertical line represents a given poverty threshold. The poverty rate is the area below the blue line on the left of the poverty threshold. The blue distribution displays the same level of inequality than the red dashed distribution but a lower share of poor individuals.

\section{Indicators}

Absolute poverty (provided by Istat on the basis of the HBS): A household is in absolute poverty if its consumption expenditure is lower or equal to the monetary value of a basket of goods and services considered as essential to avoid severe forms of social exclusion. The monetary value of the basket of absolute poverty is reviewed every year in the light of trend in prices; it differs across household's composition, age structure, macro-area and place of residence.

Gini index (provided by Istat on the basis of the EU-SILC and by the Bank of Italy on the basis of the SHIW): It measures the extent to which the distribution of income among individuals or households within an economy deviates from a perfectly equal distribution. The Gini index measures the area between the Lorenz curve and the hypothetical line of absolute equality, expressed as a percentage of the maximum area under the line. A Gini index of zero represents perfect equality and 100, perfect inequality.

Decomposition of the Gini index by subgroups is not an easy task. However, when the income distribution of the groups do not overlap and are distinct, the decomposition by group is intuitive (the rank correlation of the income distribution is zero; P. Lambert e J. Aronson, Inequality Decomposition Analysis and the Gini Coefficient Revisited, Economic Journal, 103, issue 420, 1993). This condition is met when we split the population between 
those who live in households without labour income and individuals in families with positive labour earnings.

Share of adults (18-59 y.o.) or children (0-17 y.o.) living in jobless households (provided by Eurostat on the basis of the European LFS): A household is jobless if no working age adult is employed (see Appendix A for a more detailed definition). The reference population is made of those families in which there is at least one working age adult; for example, families composed by only retirees are not considered. A working age adult has to meet the following conditions: 1) she is between 18 and 59 years old; 2) she is not a fulltime student with less than 25 years old living with parents. Two statistics are provided by Eurostat: the proportion of children (0-17 y.o.) and that of individuals (18-59 y.o.) living in jobless households.

Relative poverty (provided by Istat on the basis of the HBS): A household is in relative poverty if its consumption expenditure is lower or equal a poverty line; the poverty line is set such that it defines as poor a household of two components with a consumption expenditure level lower or equal to the mean per-capita consumption expenditure. To define the relative poverty line for different household sizes an equivalence scale is used (Carbonaro equivalence scale) to take into account different needs and economies/diseconomies of scale that can be achieved in bigger/smaller households.

Risk of poverty or social exclusion (provided by Eurostat on the basis of the EU-SILC): People at risk of poverty or social exclusion were in at least one of the following situations:

- $\quad$ at risk of poverty after social transfers (income poverty), or

- severely materially deprived; or

- living in households with very low work intensity.

Income poverty: Equivalised disposable income (after social transfer) below the at-riskof-poverty threshold, which is set at 60 per cent of the national median equivalised disposable income after social transfers.

Severely materially deprivation: Inability to pay for at least four of the following items: 1) to pay their rent, mortgage or utility bills; 2) to keep their home adequately warm; 3) to face unexpected expenses; 4) to eat meat or proteins regularly; 5) to go on holiday; 6) a television set; 7) a washing machine; 8) a car; 9) a telephone.

Household with very low work intensity: Household where working age (18-59 y.o.) individuals worked less than 20 per cent of their total potential during the previous 12 months. The work intensity of a household is the ratio of the total number of months that all working-age household members have worked during the income reference year and the total number of months the same household members theoretically could have worked in the same period. Students in the age group between 18 and 24 years are not 
considered working age. Households composed only of children, of students aged less than 25 and/or people aged 60 or more are completely excluded from the indicator calculation.

\section{Appendix B: Data definitions}

Monthly wage (definition from the questionnaire, variable RETRIC): Net salary earned last month with the exception of other monthly payments $\left(13^{\text {th }}\right.$ or $14^{\text {th }}$ month's salary, etc.) and those extra-payments not regularly included in the monthly pay (productivity premium, extraordinary overtime, overdue, etc.).

Italian wording: Retribuzione netta del mese scorso escluse altre mensilità (tredicesima, quattordicesima, ecc.) e voci accessorie non percepite regolarmente tutti i mesi (premi di produttività annuali, arretrati, indennità per missioni, straordinari non abituali, ecc.)

$\square$ Fino a 250 euro

$\square 260$

$\square 270$

$\square$-------------

口 -------------

2980

口 2990

3000 euro o più 